\title{
Prevalence of asthma control among adults in France, Germany, Italy, Spain and the UK
}

\author{
P. Demoly*, P. Paggiaro\#, V. Plaza", S.C. Bolge ${ }^{+}$, H. Kannan ${ }^{+}$, \\ B. Sohier ${ }^{\S}$ and L. Adamek ${ }^{\S}$
}

ABSTRACT: The objectives of this article were to estimate the prevalence of asthma control and describe the characteristics of at least well-controlled (ALWC) versus not well-controlled (NWC) asthmatics.

Data were obtained from the European National Health and Wellness Survey, an internet-based, cross-sectional study of 37,476 adults in France, Germany, Italy, Spain and the UK. Analysis was limited to 2,337 respondents who self-reported a physician diagnosis. Based on the Asthma Control Test $(A C T)$, respondents were grouped as ALWC (ACT $\geqslant 20)$ and NWC (ACT $\leqslant 19)$.

The prevalence of diagnosed asthma across five countries was estimated to be $5.8 \%$ (14 million extrapolated for the European Union population). Of these, 50.4\% (7.1 million) were NWC. Compared with ALWC, NWC were older (15.8 versus 15.0\%; $p<0.001$ ), less likely to be college educated (28.7 versus $36.3 \% ; p<0.001)$ and more likely to be obese $(30.0$ versus $22.7 \% ; p<0.001)$, experience depression (28.0 versus $18.7 \%$; $p<0.001$ ) and smoke (34.7 versus $25.0 \% ; p<0.001$ ). The NWC had more occasions of contact with healthcare providers and were more likely to use controller and rescue medications, but with less adherence.

A substantial portion of asthmatics are NWC. However, the proportion of NWC asthmatics found in this study was less than in previously reported. Patients and physicians need to be educated on the importance of asthma control and adherence to treatments.

KEYWORDS: Asthma control, asthma control test, National Health and Wellness Survey, prevalence

$\mathrm{T}$ o date, the literature indicates that $\sim 300$ million people worldwide are affected by asthma [1]. Prevalence varies by country and has been estimated to be $7 \%$ in France and Germany [1], $8 \%$ in the USA [2] and $15-18 \%$ in the UK [1].

While asthma presents a global public health issue with respect to the high prevalence estimates, there is also a significant burden of illness associated with asthma. A study by ACCORDINI et al. [3] indicates an increased burden of illness associated with asthma, with particular negative consequences being decreased health-related quality of life, lost work productivity, impairment of daily activity and increased health resource utilisation in Europe. The total annual cost of asthma is estimated to be $€ 17.7$ billion in Europe. Of this, $€ 3.8$ billion is for outpatient care, $€ 3.6$ billion for prescription drugs, $€ 0.5$ billion for in-patient care and $€ 9.8$ billion for indirect costs associated with work impairment and productivity losses [4]. As prevalence and cost of care increase, the economic burden of asthma will also increase [4].

Several studies now indicate that the burden of illness is not necessarily associated with asthma itself but with a lack of asthma control. The National Health, Lung and Blood Institute and the World Health Organization established the Global Initiative for Asthma (GINA) guidelines in 1995 to specifically address the issue of asthma control, by helping patients and physicians choose the appropriate treatment options [5]. The negative effects of inadequate asthma control range from increased risk of exacerbations and emergency room (ER) visits, to hospitalisation and death [1].

Despite the variety of treatment options available and the almost annual publication of GINA guidelines, the evidence indicates a lack of asthma control. In 1999, the AIRE (Asthma Insight and Reality Europe) study was conducted to assess the level of asthma control in seven
AFFILIATIONS

${ }^{*}$ Clinical Dept of Allergology, Maladies Respiratoires, INSERM U657, Hôpital Arnaud de Villeneuve, University Hospital of Montpellier Montpellier, and ${ }^{\S}$ GlaxoSmithKline, Centre of Excellence in Respiratory Diseases Marly le. Roi, France "Pneumology Section, Cardiothoracic Department University of Pisa, Pisa, Italy. - Servei de la Pneumologia, Hospital de la Santa Creu and Sant Pau Universitat Autonoma, Barcelona, Spain. ${ }^{+}$Consumer Health Sciences, Princeton, NJ, USA.

CORRESPONDENCE S.C. Bolge

Consumer Health Sciences

1 Independence Way

Suite 220

Princeton, $08540 \mathrm{NJ}$ USA

E-mail: Susan.bolge@ chsinternational.com

Received:

March 052009

Accepted after revision:

March 062009

SUPPORT STATEMENT

The National Health and Wellness Survey (NHWS) is conducted and wholly owned by Consumer Health Sciences (Princeton, NJ, USA).

GlaxoSmithKline licensed access to NHWS and funded the analysis for and preparation of this paper.

PROVENANCE

Publication of this peer-reviewed article was made possible by funding from GlaxoSmithKline, France (article sponsor, European Respiratory Review issue 112).

European Respiratory Review Print ISSN 0905-9180 Online ISSN 1600-0617 
European countries [6]. The study determined the level of asthma control in the 12 months prior to interview, based on the GINA guidelines. The results indicated that in the $5 \mathrm{yrs}$ between the GINA guidelines and the AIRE study, only $5.1 \%$ of adult patients had their asthma controlled [6].

It has been more than 10 yrs since the GINA guidelines were made available [5]. During this time, various changes have occurred, including the launch of combination therapies and the creation of new GINA guidelines highlighting control of asthma as the composite goal of treatment. There exists a need to determine whether asthma control has improved in light of these developments. The purpose of this review is to estimate the prevalence not only of asthma, but of asthma sufferers who are well-controlled versus not well-controlled 10 yrs after the publication of the GINA guidelines in five European countries: France, Germany, Italy, Spain and the UK. We will also describe the demographic, disease and treatment characteristics of the well-controlled and not well-controlled asthma sufferers across the five countries.

\section{METHODS}

\section{Study design}

Data were obtained from the 2006 European National Health and Wellness Survey (NHWS; Consumer Health Sciences, Princeton, NJ, USA). The European NHWS is an annual, crosssectional study of the health status, attitudes, behaviours and outcomes of the adult (age $\geqslant 18 \mathrm{yrs}$ ) populations in France, Germany, Italy, Spain and the UK. The NHWS sample was identified through an internet-based consumer panel maintained by Lightspeed Research (Princeton, NJ, USA). The sampling frame consisted of quotas based on sex and age that reflected the demographic distribution of each country. Data were collected through self-administered, web-based questionnaires. Due to the low risks associated with survey research, the 2006 European NHWS was not submitted for approval by an International Review Board; however, information about confidentiality and the voluntary nature of participation was included in the introduction to the survey. Respondents who self-reported having diagnosed asthma were included in the following analyses.

\section{Study measures}

\section{Asthma control}

Asthma control during the past 4 weeks was assessed using the Asthma Control Test (ACT). The ACT is a patientadministered instrument developed for use in clinical care settings. It is a validated and reliable metric for patients aged $\geqslant 12$ yrs. ACT scores range from poor control (5) to total asthma control (25). At least well-controlled asthma is defined as an ACT score of $\geqslant 20$ and not well-controlled asthma is defined as an ACT score of $\leqslant 19$ [7].

\section{Sample characteristics and healthcare attitudes}

Respondents provided information about their demographics, general health characteristics and asthma specific disease characteristics. Demographics included sex, age, marital status, education and country of residence. Health characteristics included height and weight, which were used to calculate body mass index (BMI), smoking status and self-reported experience of depression in the past 12 months. Asthma specific disease characteristics included the number of years since diagnosis of asthma by a physician, self-rated asthma severity and number of times asthma was discussed with physician in the past year.

Respondents were also presented with a list of 17 attitudinal statements about health and healthcare to which they responded on a five-point scale, on which $1=$ strongly disagree through to $5=$ strongly agree. Responses of a four or five were categorised as agreement with the statement.

\section{Medication use}

Respondents with asthma were asked to indicate which medications they use for asthma from a prompted list (see the Appendix). For each medication selected, respondents also reported how many days they had used the medication in the past month. Respondents were classified as treated if they reported using any medication. Respondents were categorised as using rescue medication if they reported currently using any of the following medications at least eight times in the past month, which averages to twice per week: formoterol, pirbuterol, salbutamol, terbutaline. Respondents were categorised as using controller medications if they used a nonrescue medication on at least 24 days in the past month, which averages to using medication at least 6 days per week.

\section{Medication adherence}

Medication adherence was assessed using the Morisky Medication Adherence Scale (MMAS). The MMAS was originally validated among hypertension patients, but has since been found to be valid and reliable in other patient populations. The MMAS consists of four items assessing reasons for nonadherence: forgetfulness, carelessness, feeling better and feeling worse. The overall MMAS score consists of five points from $0=$ compliant to $4=$ noncompliant [8].

TABLE 1 Prevalence of asthma control extrapolated to the European Union population (in millions)

\begin{tabular}{|c|c|c|c|c|c|c|}
\hline & All Countries & France & Germany & Italy & Spain & UK \\
\hline Diagnosed asthma (\% total population) & $14.07(5.8)$ & $2.28(4.8)$ & $3.27(4.8)$ & $2.26(4.7)$ & $1.58(4.8)$ & $4.67(10.0)$ \\
\hline At least well-controlled (\% diagnosed) & $6.98(49.6)$ & $1.15(50.5)$ & $1.13(34.7)$ & $1.07(47.2)$ & $0.95(59.8)$ & $2.68(57.3)$ \\
\hline Treated asthma (\% diagnosed asthma) & $11.03(78.4)$ & $1.62(71.0)$ & $2.60(79.6)$ & $1.37(60.6)$ & $1.26(79.4)$ & $4.18(89.5)$ \\
\hline Not well-controlled (\% treated) & $6.07(55.0)$ & $0.91(55.9)$ & $1.88(72.3)$ & $0.84(61.4)$ & $0.57(45.0)$ & $1.88(44.8)$ \\
\hline
\end{tabular}


TABLE 2 Components of asthma control among diagnosed asthma sufferers across all countries

Total

Not well-controlled

In the past 4 weeks, how much of the time did your asthma keep you from getting as much done at work, school or at home?

All of the time

$0.14(1.0)$ 2.0

Most of the time

$0.57(4.1)$

8.1

Some of the time

$1.86(13.2)$

24.7

A little of the time

3.49 (24.8)

35.0

None of the time

8.01 (56.9)

During the past 4 weeks, how often have you had shortness of breath?

More than once a day

Once a day

$1.38(9.8)$

18.1

3-6 times a week

$1.70(12.0)$

19.5

Once or twice a week

5.11 (36.3)

Not at all

During the past 4 weeks, how often did your asthma symptoms (wheezing, coughing, shortness of breath, chest tightness or pain) wake you up at night, or earlier than usual in the morning?

$\geqslant 4$ nights a week

2-3 nights a week

$1.25(8.9)$

Once a week

$1.98(14.1)$

Once or twice

$1.12(8.0)$

During the past 4 weeks how often have you used your rescue inhaler or nebuliser medication, such

as albuterol?

$\geqslant 3$ times per day

$1.11(7.9) \quad 15.4$

1-2 times per day

$3.31(23.6)$

39.5

2-3 times per week

$1.95(13.9)$

20.5

Once a week or less

$3.08(21.9)$

13.5

Not at all

$4.61(32.7) \quad 11.1$

How would you rate your asthma control during the past 4 weeks?

Not at all controlled

$1.10(7.8)$

Poorly controlled

\section{Statistical analysis}

Prevalence estimates were computed using frequency weights, based on sex, age and country of residence. The known population was defined using the 2006 mid-year population sex and age estimates for each of the five countries [9]. In addition, an asthma control index was computed as the ratio of at least well-controlled to not well-controlled asthma sufferers.

Asthma sufferers who were not well-controlled were compared to those who were well-controlled using unweighted data. The Chi-squared test was used to test for significant differences in categorical variables, and unpaired t-tests were used to test for significant differences in continuous variables. No adjustments were made for multiple comparisons.

\section{RESULTS}

\section{Asthma prevalence and control}

There were 37,476 respondents to the 2006 European NHWS. Of these 2,337 were subjects with self-reported, physician-diagnosed asthma. Applying frequency weights, the prevalence of diagnosed asthma across the five European countries covered by NHWS was $5.8 \%$ of the adult population or $\sim 14$ million people. The proportion of sufferers was similar in France $(4.8 \%, 2.28$ million), Germany ( $4.8 \%, 3.27$ million), Italy $(4.7 \%, 2.26$ million) and Spain $(4.8 \%, 1.58$ million). However, the UK had a higher proportion of asthma sufferers than the other four countries $(10.0 \%, 4.67$ million; table 1$)$.

Components of asthma control for the past 4 weeks assessed by the ACT included: impact on work, school and home activities; frequency of symptoms; impact on sleep; use of rescue medication; and perception of asthma control. Across countries, $43.1 \%$ of asthma sufferers experienced at least some impact on work, school or home activities from their asthma. Shortness of breath was experienced at least once a day by $26.0 \%$ sufferers, with $31.0 \%$ reporting waking at least once a week due to asthma symptoms. Nearly half $(45.4 \%)$ of asthma sufferers use a rescue inhaler or nebuliser more than once a week (table 2). 


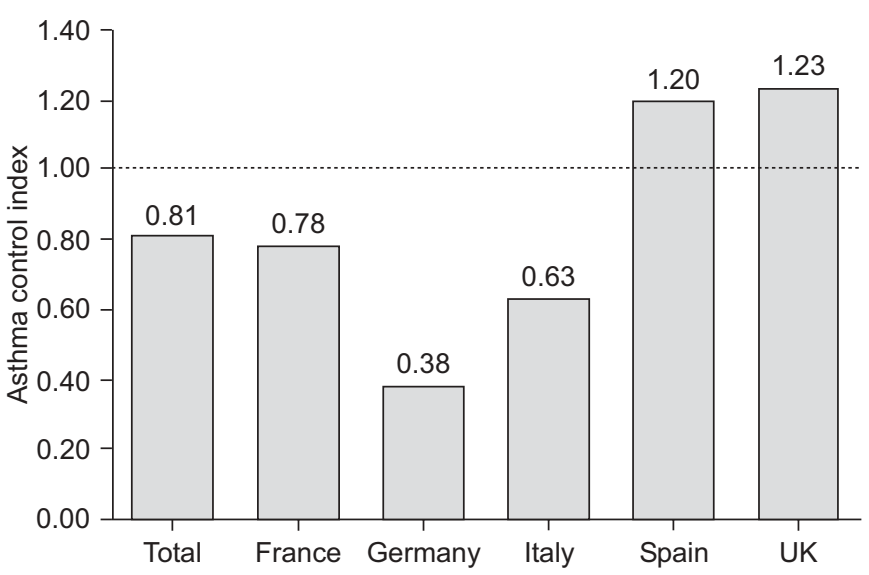

FIGURE 1. Asthma Control Index. An asthma control index was computed as the ratio of at least well-controlled to not well-controlled asthma sufferers. An index of $>1$ equates to a greater proportion of at least well-controlled, and an index of $<1$ equates to a greater proportion of not well-controlled. When the proportion of at least well-controlled and not well-controlled are equal, the asthma control index is equal to 1.

When asked to rate individual asthma control as part of the ACT, 35.3\% of diagnosed asthma sufferers rated their asthma as not well-controlled, equating to 3.97 million sufferers across the five European countries. However, control is overestimated by patients when comparing the individual control item to the total ACT score. Based on the total ACT score, of which patient

\begin{tabular}{|c|c|c|c|}
\hline \multirow[t]{3}{*}{ TABLE 3} & $\begin{array}{l}\text { hic and health } \\
\text { ferers by cont }\end{array}$ & $\begin{array}{l}\text { characteristics } \\
\text { ol }\end{array}$ & \multirow{3}{*}{ p-value ${ }^{\#}$} \\
\hline & \multicolumn{2}{|c|}{ Diagnosed asthma } & \\
\hline & $\begin{array}{c}\text { Not } \\
\text { well-controlled }\end{array}$ & $\begin{array}{c}\text { At least } \\
\text { well-controlled }\end{array}$ & \\
\hline Subjects $n$ & 1159 & 1178 & \\
\hline Female & 62.6 & 63.6 & 0.637 \\
\hline Age yrs & $44.54 \pm 15.8$ & $40.94 \pm 15.0$ & $<0.001$ \\
\hline Married or living with partner & 59.0 & 61.5 & 0.212 \\
\hline College degree & 28.7 & 36.3 & $<0.001$ \\
\hline \multicolumn{4}{|l|}{ Country of residence } \\
\hline France & 19.8 & 21.0 & 0.468 \\
\hline Germany & 26.5 & 15.2 & $<0.001$ \\
\hline Italy & 9.8 & 10.1 & 0.830 \\
\hline Spain & 8.0 & 11.4 & 0.006 \\
\hline UK & 35.9 & 42.4 & 0.001 \\
\hline Overweight & 32.8 & 33.8 & 0.612 \\
\hline Obese $^{+}$ & 30.0 & 22.7 & $<0.001$ \\
\hline Smoked in the past & 33.9 & 32.3 & 0.421 \\
\hline Currently smoke & 34.7 & 25.0 & $<0.001$ \\
\hline Experience depression $^{\S}$ & 28.0 & 18.7 & $<0.001$ \\
\hline
\end{tabular}

Data are presented as mean \pm SD or $\%$, unless otherwise stated. ${ }^{\#}$ : computed using Chi-squared for comparisons of percentages and t-tests for comparisons of means; ' $\geqslant 30 \mathrm{~kg} \cdot \mathrm{m}^{-2} ;$ s: self reported. perception of control is only one component, half $(50.4 \%)$ of the sufferers were not well-controlled. This equated to 7.09 million not well-controlled asthma sufferers across the five European countries. Comparing the asthma control index by country, the UK has the greatest level of control, closely followed by Spain. The lowest rates of control were among asthma sufferers in Germany (fig. 1). There were 11 million asthma sufferers who self-reported treating their asthma with prescription controller or rescue medication at the time of the survey across the five European countries. Among these, an even greater proportion $(55 \%)$ were not well-controlled among the total asthma sufferers (table 1 ).

\section{Demographic and health characteristics}

Table 3 summarises the demographic and health profiles of diagnosed asthma sufferers by asthma control. Among the diagnosed asthma sufferers, those who were not wellcontrolled $(n=1,159)$ were significantly $(p<0.001)$ older and less likely to be college educated than the at least wellcontrolled $(n=1,178)$. As opposed to the at least well-controlled asthma sufferers, the not well-controlled asthma sufferers were also more likely to reside in Germany and less likely to reside in Spain or the UK. Sex, marital status and residing in France or Italy did not significantly vary by asthma control.

Asthma sufferers who were not well-controlled appeared to have a worse health profile than those who were at least wellcontrolled. Obesity, defined as BMI $\geqslant 30 \mathrm{~kg} \cdot \mathrm{m}^{-2}$, was more prevalent among asthma sufferers who were not wellcontrolled than those at least well-controlled (30.0 versus $22.7 \%, \mathrm{p}<0.001)$. Self-reported experience of depression in the past 12 months was also more prevalent among asthma sufferers who were not well-controlled (28.0 versus $18.7 \%$, $\mathrm{p}<0.001)$. Asthma sufferers who were not well-controlled were significantly more likely to currently smoke compared with asthma sufferers who were at least well-controlled (34.7 versus $25.0 \%, \mathrm{p}<0.001)$.

\section{Healthcare attitudes}

Table 4 summarises the healthcare-related attitudes of diagnosed asthma sufferers by asthma control. Among diagnosed asthma sufferers, those who were not well-controlled were significantly $(p<0.001)$ less likely to believe that they were in control of their own health and more likely to be fatalistic than the at least well-controlled. Specifically, asthma sufferers who were not well-controlled were less likely to feel in control of their health or to believe that they can stay healthy if they take the right actions. They also were more likely to believe that luck plays a large part in determining time to recovery and that no matter what actions are taken, sickness will occur if it is fated to occur.

Not well-controlled asthma sufferers were less satisfied with their healthcare than at least well-controlled sufferers. However, not well-controlled asthma sufferers were more open to prescription medications than those at least wellcontrolled. Specifically, $65 \%$ of not well-controlled sufferers would ask their physician for prescription medication, $41 \%$ would participate in a clinical drug trial and $57 \%$ would take a long-term, daily medication to prevent a condition for which they may be at risk. 
TABLE 4 Healthcare attitudes of asthma sufferers by control

\begin{tabular}{|c|c|c|c|}
\hline Agree with statement & $\begin{array}{c}\text { Not } \\
\text { well-controlled }\end{array}$ & $\begin{array}{c}\text { At least } \\
\text { well-controlled }\end{array}$ & p-value ${ }^{+}$ \\
\hline I am in control of my health & 49.2 & 58.5 & $<0.001$ \\
\hline If I take the right actions, I can stay healthy & 50.2 & 57.9 & $<0.001$ \\
\hline No matter what I do, if I am going to get sick, I will get sick & 33.5 & 29.1 & 0.023 \\
\hline Luck plays a big part in determining how soon I will recover from an illness & 14.6 & 11.3 & 0.018 \\
\hline My friends consider me a good source of health information & 29.5 & 31.2 & 0.387 \\
\hline Sometimes I take other people's medication even though it is not prescribed for me & 11.2 & 9.8 & 0.281 \\
\hline I frequently forget to take medications prescribed by my physician & 15.3 & 15.4 & 0.905 \\
\hline I frequently switch prescription medications & 5.3 & 3.6 & 0.037 \\
\hline I am doing all I can to maintain a healthy diet & 52.8 & 53.6 & 0.712 \\
\hline I would try acupuncture & 53.7 & 52.2 & 0.480 \\
\hline I am very satisfied with the healthcare I receive & 47.0 & 55.6 & $<0.001$ \\
\hline I would participate in a clinical drug trial & 40.8 & 33.0 & $<0.001$ \\
\hline $\begin{array}{l}\text { I would take a prescription medication every day for the rest of my life to prevent a } \\
\text { disease I may be at risk for }\end{array}$ & 56.6 & 51.5 & 0.014 \\
\hline
\end{tabular}

Data are presented as \%, unless otherwise stated. ${ }^{\#}: n=1,159 ;{ }^{\natural}: n=1,178 ;^{+}:$computed using Chi-squared test.

\section{Disease and treatment characteristics}

Regardless of the level of control, adult asthma sufferers were diagnosed, on average, 17 yrs ago. Asthma sufferers who were not well-controlled were significantly less likely to self-rate their condition as mild to intermittent compared with those who are at least well-controlled. The not well-controlled sufferers were more likely to have spoken to their physician on two or more occasions in the past 12 months about their asthma. They also had more visits to traditional medical providers and were more likely to have visited an ER in the past 6 months (table 5).

Asthma sufferers who were not well-controlled were significantly more likely to currently use both controller medication and rescue medication. Among treated asthma sufferers, those who were not well-controlled were significantly $(p=0.015)$ less adherent to their medications, as measured by the MMAS, than those who were well-controlled.

\section{DISCUSSION}

Despite the establishment of the GINA guidelines in 1995, the AIRE study indicated that the majority of asthma sufferers in seven European countries had not established adequate asthma control [6]. The GINA guidelines dictate that asthma control can be achieved and maintained among the majority of asthmatics [6]. The current analysis was conducted to determine levels of control in light of not only new therapies but also updated GINA guidelines.

The results of the current analysis are aligned with previous research with respect to prevalence estimates, as well as sample characteristics. The overall prevalence of diagnosed asthma was $6 \%$ in the NHWS versus $3.6 \%$ in AIRE [6]. In this review, nearly $80 \%$ of asthma sufferers were treated and $~ 50 \%$ of asthma sufferers were categorised as "not well-controlled". Among those who were treated, 55\% remain not well-controlled compared with $95 \%$ in the AIRE study [6]. While this seems to indicate an improvement in the level of control since the AIRE study, it also highlights the disparity between available treatment options and the lack of adequate management.

Our findings were compared to others conducted recently. The Reality of Asthma Control (TRAC) study [10], conducted in Canada in 2004 , found that $\sim 53 \%$ of adults aged $18-54$ yrs who reported having asthma were uncontrolled and asthma control was being assessed by symptom-based guidelines. The INSPIRE study, conducted in eight European countries and Canada, Australia and the USA, also found similar results, with 51\% not being controlled [11], and control being assessed by the Asthma Control Questionnaire. These results are consistent with those of this review. However, there are variations in asthma control by country, ranging from as high as $65 \%$ in Germany to as low as $40 \%$ in Spain. These variations may be associated with differences in healthcare systems, treatment standards or cultural aspects of each country.

In addition, this review illustrates the association of asthma control with disease, treatment, and health attitudes and characteristics. Sufferers who are not well-controlled are more likely to identify greater disease severity, be obese, smoke and experience depression than the well-controlled sufferers. Physicians should be aware of the needs of patients with this 
TABLE 5 Disease and treatment characteristics of asthma sufferers by control

\begin{tabular}{|c|c|c|c|}
\hline & \multicolumn{2}{|c|}{ Diagnosed asthma } & \multirow[t]{2}{*}{ p-value ${ }^{\#}$} \\
\hline & Not well-controlled & At least well-controlled & \\
\hline Subjects $n$ & 1159 & 1178 & \\
\hline Years since diagnosis & $17.0 \pm 13.7$ & $16.7 \pm 12.9$ & 0.616 \\
\hline Asthma severity" & & & $<0.001$ \\
\hline Moderate persistent & 31.9 & 8.6 & \\
\hline Severe persistent & 7.5 & 1.2 & \\
\hline Number of instances spoken with doctor about asthma in past year & & & $<0.001$ \\
\hline 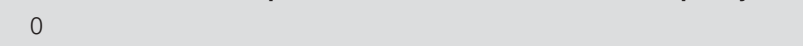 & 11.7 & 29.5 & \\
\hline 1 & 20.7 & 33.7 & \\
\hline 2 & 24.4 & 21.3 & \\
\hline Use of controller medication & 44.1 & 25.8 & $<0.001$ \\
\hline MMAS, among treated & $1.49 \pm 1.33$ & $1.34 \pm 1.28$ & 0.015 \\
\hline Ever forgotten to take medicine & 41.5 & 33.6 & $<0.001$ \\
\hline Careless about taking medicine & 33.5 & 27.3 & 0.003 \\
\hline Stop taking medicine when feel better & 49.0 & 50.5 & 0.500 \\
\hline Stop taking medicine when feel worse & 24.8 & 22.7 & 0.279 \\
\hline \multicolumn{4}{|l|}{ Healthcare resource use in past 6 months } \\
\hline Traditional medical provider visits & $9.93 \pm 11.59$ & $6.48 \pm 7.96$ & $<0.001$ \\
\hline Visited ER & 25.5 & 17.7 & $<0.001$ \\
\hline
\end{tabular}

Data are presented as mean \pm SD or \%, unless otherwise stated. MMAS: Morisky Medication Adherence Scale; ER: emergency room. * : computed using Chi-squared for comparisons of percentages and t-tests for comparisons of means; ' : self reported.

profile, especially as the not well-controlled sufferers continue to be more open to seeking treatment, are more likely to use medication and have more occasions of contact with providers. However, the not well-controlled sufferers report poorer treatment adherence and more fatalistic attitudes, which may further jeopardise their disease control. Physician and patient education programmes need to address the importance of treatment adherence for asthma control. Physicians also need to understand that while patients acknowledge the burden of their condition, they do not always realise their level of asthma control appropriately. Far fewer patients self-rate their asthma as uncontrolled compared to those who truly are not wellcontrolled.

The compliance data showed that better adherence was associated with better asthma control. Of the not wellcontrolled sufferers only $32 \%$ were completely adherent. Specifically, of the asthma sufferers who were not wellcontrolled, $42 \%$ forgot to take medication, $34 \%$ were careless about taking medication, $49 \%$ stopped taking medication when they felt better and $25 \%$ stopped taking medication when they felt worse (table 5).

As with all studies, there are potential biases inherent in the NHWS sample and study design. The diagnosis of asthma, level of control and demographics, disease and treatment characteristics were all self-reported. Data were not verified against clinical diagnostics, and there was the possibility of recall bias. However, the prevalence estimate of self-reported asthma diagnosis in the NHWS was consistent with other studies [1]. In addition, asthma control and medication adherence were assessed using metrics that have been shown to be valid and reliable for self-reporting by patients.

NHWS subjects were recruited through an internet-based panel and, therefore, the sample may not be fully representative of the population in France, Germany, Italy, Spain and the UK who do not have internet access. In 2006, a substantial portion of the European population had internet access: $49.6 \%$ in France, $46.7 \%$ in Germany, $49.6 \%$ in Italy, $42.8 \%$ in Spain, and $56.0 \%$ in the UK [12]. In order to address this bias, the NHWS sampling frame consisted of quotas for sex and age that were reflective of the demographic distribution within each country.

While the results of this analysis indicate that asthma control has improved in Europe since the establishment of the GINA guidelines, more concerted efforts in achieving and maintaining control are still needed. Since guidelines have focused on appropriate treatment options, further research is needed to better understand obstacles of asthma control from the patient perspective, such as nonadherence with treatment. The understanding gained from such research could contribute 
substantially to patient education, which in turn could lead to better management of asthma by the patients. Additionally, not well-controlled patients have greater contact with healthcare providers but remain uncontrolled, indicating that current assessments of control and care are not optimal. Findings of a recent study of asthma control as assessed by physicians on their own versus using a control questionnaire illustrated that physicians often overestimate asthma control [13]. Future consideration should be placed on educating primary care physicians on the importance of asthma control and implementation of the GINA guidelines.

\section{STATEMENT OF INTEREST}

B. Sohier and L. Adamek are employees of GlaxoSmithKline. P. Demoly has received fees as a speaker and advisory board member from ALK, Almirall, AstraZeneca, GlaxoSmithKline, Merck, Mylan, Shering Plough, Stallergènes, Therabel and UCB. P. Paggiaro, in the last 5 yrs, has received funds from AstraZeneca, Abbott, Boehringer Ingelheim, Chiesi Pharmaceutical, GlaxoSmithKline, Menarini, Merck Sharp \& Dohme, Novartis, Nycomed, Sigma-Tau and Valeas, for speaking at congresses, undertaking institutional research activities and acting as consultant on scientific boards. V. Plaza has been funded to travel to the ERS and ATS congress by AstraZeneca and GlaxoSmithKline. He has received an educational grant from GlaxoSmithKline, AstraZeneca and Lab. Dr. Esteve, and received a fee for speaking and research from GlaxoSmithKline, AstraZeneca and MSD.

\section{APPENDIX: PROMPTED LISTS OF MEDICATIONS PROVIDED TO RESPONDENTS IN EACH COUNTRY France}

Asmanex (mometasone), Atrovent (ipratropium bromide), Beclometasone, Becotide (beclometasone), Bricanyl (terbutaline), Bronchodual (fenoterol/ipratropium bromide), Combivent (salbutamol/ipratropium bromide), Flixotide (fluticasone), Foradil (formoterol), Maxair (pirbuterol), Pulmicort (budesonide), Salbutamol, Seretide (fluticasone/salmeterol), Serevent (salmeterol), Singulair (montelukast), Symbicort (budesonide/ formoterol), Theophylline, Ventoline (salbutamol), other (specified).

\section{Germany}

Asmanex (mometason), Atrovent (ipratropium bromide), Beclomet (beclometason), Berodual (fenoterol/ipratropium bromide), Bricanyl (terbutaline), Flutide (fluticasone), Foradil (formoterol), Natriumcromoglicat/reproterol, Pulmicort (budesonide), Servent (salmeterol), Singulair (montelukast), Spiriva (tiotropium bromide), Sultanol (salbutamol), Symbicort (budesonide/formoterol), Theophyllin, Viani (fluticasone/salmeterol), other (specified).

\section{Italy}

Accoleit (zafirlukast), Asmanex (mometasone), Atem (ipratropium bromide), Breva (ipratropium bromide/salbutamol), Duovent (fenoterol/ipratropium bromide), Flixotide (fluticasone), Foradil (formoterol), Oxis (formoterol), Pulmaxan (budesonide), Seretide (fluticasone/salmeterol), Serevent (salmeterol), Singulair (montelukast), Spiriva (tiotropium bromide), Symbicort (budesonide/formoterol), Terbasmin (terbutaline), Ventolin (salbutamol), other (specified).

\section{Spain}

Accolate (zafirlukast), Asmanex (mometasone), Atrovent (ipratropium bromide), Combivent (ipratropium bromide/ salbutamol), Berodual (fenoterol/ipratropium bromide), Flixotide (fluticasone), Oxis (formoterol), Pulmicort (budesonide), Seretide (fluticasone/salmeterol), Serevent (salmeterol), Singulair (montelukast), Spiriva (tiotropium bromide), Symbicort (budesonide/formoterol), Terbasmin (terbutaline), Ventolin (salbutamol), other (specified).

\section{UK}

Accolate (zafirlukast), Asmanex (mometasone), Atrovent (ipratropium bromide), Beclometasone, Bricanyl (terbutaline), Combivent (ipratropium bromide/salbutamol), Duovent (fenoterol/ipratropium bromide), Flixotide (fluticasone), Oxis (formoterol), Pulmicort (budesonide), Salbutamol, Seretide (fluticasone/salmeterol), Serevent (salmeterol), Singulair (montelukast), Spiriva (tiotropium bromide), Symbicort (budesonide/formoterol), Theophylline, Ventolin (salbutamol), other (specified).

\section{REFERENCES}

1 Peters SP, Ferguson G, Deniz Y, et al. Uncontrolled asthma: a review of prevalence, disease burden and options for treatment. Respir Med 2006; 100: 1139-1151.

2 Centers for Disease Control and Prevention. 2007 Adult asthma data: prevalence tables and maps. www.cdc.gov/ asthma/brfss/07/brfssdata.htm Date last accessed: April 25, 2008.

3 Accordini S, Corsico A, Cerveri I, et al. The socio-economic burden of asthma is substantial in Europe. Allergy 2008; 63: 116-124.

4 Asthma. In: Loddenkemper R, Gibson GJ, Sibille Y, eds. European Respiratory Society/European Lung Foundation. European Lung White Book. The First Comprehensive Survey on Respiratory Health in Europe. Sheffield, ERSJ, 2003; pp. 16-25.

5 Bousquet J, Clark TJ, Hurd S, et al. GINA guidelines on asthma and beyond. Allergy 2007; 62: 102-112.

6 Rabe KF, Vermeire PA, Soriano JB, et al. Clinical management of asthma in 1999: the Asthma Insights and Reality in Europe (AIRE) study. Eur Respir J 2000; 16: 802-807.

7 Nathan RA, Sorkness CA, Kosinski M, et al. Development of the asthma control test: a survey for assessing asthma control. J Allergy Clin Immunol 2004; 113: 59-65.

8 Morisky DE, Green LW, Levine DM. Concurrent and predictive validity of a self-reported measure of medication adherence. Med Care 1986; 24: 67-74.

9 U.S. Census Bureau. International Data Base (IDB). www.census.gov/ipc/www/idb/ Date last accessed: September 15, 2006. Date last updated: August 2006.

10 FitzGerald JM, Boulet LP, McIvor RA, et al. Asthma control in Canada remains suboptimal: the Reality of Asthma Control (TRAC) study. Can Respir J 2006; 13: 253-259. 
11 Partridge MR, van der Molen $\mathrm{T}$, Myrseth SE, et al. Attitudes and actions of asthma patients on regular maintenance therapy: the INSPIRE study. BMC Pulm Med 2006; 6: 13 .

12 United Nations Statistical Division. Key Global Indicators. Internet users per 100 population (ITU estimates/SYB51). http:/ / data.un.org/Data.aspx?q=internet\&d=CDB\&f=srID: 29969 Date last accessed: April 25, 2008. Date last updated: May 22, 2008.

13 Chapman KR, Boulet LP, Rea RM, et al. Suboptimal asthma control: prevalence, detection and consequences in general practice. Eur Respir J 2008; 31: 320-325. 